\title{
Bioactive Phenolic Acid Contents Of Nanoparticle Z. Officinale Rhizome Via High-Performance Liquid Chromatography - Solid Phase Extraction (HPLC-SPE) Methods
}

\author{
Norhidayah Abdullah ${ }^{1}$, Noriham Abdullah ${ }^{2}$ and Mohammad Rusop Mahmood ${ }^{3}$ \\ Research Scholar ${ }^{1}$ and Professor ${ }^{2-3}$ \\ ${ }^{1}$ Foodservice Department, Faculty of Hotel and Tourism Management \\ ${ }^{2}$ School of Industrial Technology, Faculty of Applied Sciences \\ ${ }^{3} \mathrm{NANO}$-SciTech Centre, Institute of Science \\ Universiti Teknologi MARA Selangor, Campus Puncak Alam \\ Universiti Teknologi MARA Shah Alam \\ Selangor, Malaysia
}

\begin{abstract}
Nanotechnology is a prominent science knowledge applied in miscellaneous disciplines. The effect of nanotechnology on the phenolic profile of herbs is lacking in the literature, thus this study was conducted to assess the effect of nanotechnology on bioactive polyphenolic compounds of z. officinale (ginger) rhizome. The effect of the nanotechnology process on the content of bioactive polyphenolic compounds in the nanoparticle ginger was compared to the conventional prepared namely coarse and fine particle ginger. The phenolic acids of ginger rhizome powder (of 6 - gingerol, 8 - gingerol, 10 - gingerol, 6 - shogaol, gallic acid, chlorogenic acid, ascorbic acid, vanillic acid, ferulic acid, and p-coumaric) were identified using HPLC-SPE method. Nanotechnology process found to increase $88.03 \%$ of 6 - gingerol, $0.23 \%$ in 8 - gingerol and $100 \%$ in 10 - gingerol as shown in the nanoparticle ginger rhizome but 74\%, 34.13\% and almost 100\% decreased in the gallic acid, chlorogenic acid and pcoumaric acid respectively as compared to the conventional prepared ginger powder. Hence it can be suggested that nanotechnology significantly affects the constituents of the phenolic acid of herbs which may be beneficial for the food and pharmaceutical industry.
\end{abstract}

Key Words: Ginger, HPLC-SPE, Nanotechnology, Phenolic acids.

\section{INTRODUCTION}

The term "nanotechnology" was first used in 1974 by the late Norio Taniguchi and the concepts were provided by Richard Feynman in 1959. It has currently become a fast emerging field that involves the manufacture, processing, food and bioprocess industry through the development of materials in the nanoscale dimension of less than $100 \mathrm{~nm}$ [1]. While nanoparticle is also defining as particles in the range of $10 \mathrm{~nm}$ to $1000 \mathrm{~nm}$ [2] due to numerous successful applications by employing nanomaterial with particle size above $100 \mathrm{~nm}$. Nanotechnology process has been reported enhanced the control release of active compounds [3] [4]. Enhanced the active constituents reported in nano L. dihuang [5] and S. miltiorrhiza [6] due to nanotechnology process. Despite enhancement of phenolic acids as a result of nanotechnology process, depletion of some of the active compounds also reported. Nanotechnology process caused the folates, phytic acid, sinapic acid, as well as coumaric acid depleted as demonstrated in the wheat bran and fibre flax $[7,8]$. The compounds' stability during the nanotechnology process may contribute to the variation in the active constituents extracted.

Z. officinale Rosc rhizome (ginger) which belongs to the tropical and sub-tropical family of Zingiberaceae, originated in South East Asia $[9,10]$ and is commercially cultivated, in India, China, any many more. This plant has been cultivated for more than a thousand years for its pungent aromatic rhizome for flavour as well as antimicrobial and antioxidant properties. It is due to present of active constituents found in the Z. officinale itself. 
Gingerols are known as homologous phenolic ketones that exist as 6, 8, and 10 - gingerol are the abundantly found in Z. offinale [11]. In fresh Z. officinale rhizome, this dominant constituent consists of other gingerol derivatives in the mean ratio of 3:1:1 for 6 - gingerol, 8 - gingerol and 10 - gingerol respectively [12]. While shogaols, a dehydrated form of the gingerols and paradol, are the predominant pungent constituents found in dried Z. officinale rhizome.

Despite the remarkable benefits of $Z$. officinale rhizome, as well as the nanotechnology process, however there has been limited study conducted on the effect of nanotechnology on bioactive phenolic acids compounds of Z. officinale rhizome in literature. Thus this study was conducted to identify the effect of nanotechnology process on phenolic acids profile of $Z$. officinale rhizome.

\section{MATERIALS AND METHOD}

\subsection{Preparation of Z. officinale Rhizome Powder}

The coarse Z. officinale rhizome powder was obtained by grinding the dried Z. officinale rhizome using a food processor (MX-898, Panasonic) for $5 \mathrm{~min}$ and screened through 40 mesh sized sieve to separate the granulates. The Z. officinale rhizome powder with the mean particle size of $19.22 \mu \mathrm{m}$ was obtained and named as coarse particle (CP). Dried Z. officinale particles were then subjected to the fine milling using a hammer mill (IKA@Werile, MF10 basic) at 3000 rpm for 30 min. It was then sieved using the sieve shaker (Retsch AS 200, Germany) attached with $250 \mu \mathrm{m}$ bore diameter siever. The fine particles obtained which pass through the sieve shaker were collected. The uniform Z. officinale powder with mean size of $4.12 \mu \mathrm{m}$ were obtained and named as fine particle (FP). The fine particle powder obtained was used as the starting material for the preparation of the nanoparticle $Z$. officinale rhizome powder. The fine particle powder was milled into nanoparticle size using a planetary ball mill (Retsch PM 200, Germany) with 2 stainless steel pots with $50 \mathrm{ml}$ capacity each. Approximately $1 \mathrm{~g}$ of the powder was sealed in the pot filled with $25.0 \mathrm{~g}$ of grinding media. Commercially available zirconia beads with diameters of $2.0 \mathrm{~mm}$ were used as the grinding medium. The revolution speed of the milling pot was adjusted to $550 \mathrm{rpm}$ and the powder milled for 4 hours. The $Z$. officinale rhizome powder with mean size of $223 \mathrm{~nm}$ was obtained and labelled as nanoparticle Z. officinale rhizome powder (NP). All samples were kept in an airtight container at $4^{\circ} \mathrm{C} \pm 1^{\circ} \mathrm{C}$, prior to further analysis.

\subsection{Solid Phase Extraction Procedure (SPE)}

In this study, the Z. officinale rhizome was extracted using a solid-phase extraction (SPE) method. It is a separation process by which compounds that are dissolved or suspended in a liquid mixture are separated from other compounds according to their physical and chemical properties. This extraction method is analytically used to concentrate and purify samples prior to HPLC analysis. Initially, the C18 Sep-Pak cartridges were conditioned with $12 \mathrm{ml}$ of methanol and then washed using $18 \mathrm{ml}$ of distilled water prior to sample load. The sample extracted was then eluted with $0.1 \%$ acidified water $(0.1 \% \mathrm{HCl})$, followed by ethyl acetate. The collected filtrate was kept in the air tight container and stored at $4{ }^{\circ} \mathrm{C}$ before use.

\subsection{Preparation of Standard Solutions}

The external standard that consist of standard gingerol, 6 - gingerol, 8 - gingerol, 10 - gingerol, 6 - shogaol, gallic, chlorogenic, ascorbic, vanillic, ferulic, and p-coumaric, (-) were used to identify the presence of phenolic acid contents in the coarse, fine and nanoparticle Z. officinale rhizome powder. The selected standards are the phenolic compounds reported to be found in Z. officinale that contributed to its bioactivity $[\underline{13}, \underline{14}]$.

The individual standard stock solutions $(1000 \mu \mathrm{g} / \mathrm{ml})$ were prepared by weighing $10 \mathrm{mg}$ of each standard into $10 \mathrm{ml}$ volumetric flasks, and dissolving them in methanol HPLC grade. Stock solutions were stored at $4^{\circ} \mathrm{C}$ for not more than 2 weeks. A working standard solution $(200 \mu \mathrm{g} / \mathrm{ml})$ was prepared by using $200 \mu \mathrm{l}$ of standard stock made up to $1000 \mu \mathrm{l}$ with methanol HPLC grade to form the individual standard. A working solution was prepared daily and stored at $4^{\circ} \mathrm{C}$ prior to use. A mixed standard solution was prepared by combining $300 \mu \mathrm{l}$ of each of the individual standard solutions. Identification of 6 - gingerol, 8 - gingerol, 10 - gingerol, 6 - shogaol, gallic acid, chlorogenic acid, ascorbic acid, vanillic acid, ferulic acid and p-coumaric in the samples were based on the comparisons of retention time and UV-Vis spectra with the standards. In addition, the serial dilutions of the $1000 \mu \mathrm{g} / \mathrm{ml}$ standard were used for the preparation of $200,400,600,800 \mu \mathrm{g} / \mathrm{ml}$ working standards. All the standards used were capped and stored at $4^{\circ} \mathrm{C}$ until used.

\subsection{Preparation of Standard Solutions}

The presence of active constituents in the tested samples was quantified and analysed using an Agilent 1200 High Performance Liquid Chromatograph (Agilent, USA) consisting of a degasser, a G1315D binary pump system, an auto sampler and a G1316B TCCS1 column oven. It was coupled with a UV-Vis detector and controlled by Agilent Chemstation ${ }^{\circledR}$ software. Separation of coarse, fine and nanoparticle Z. officinale were achieved using a Zorbax Eclipse XDB-C18 column (particle size 5 $\mu \mathrm{m}, 250 \times 4.6)$ equipped with a Zorbax $\mathrm{C} 18$ analytical guard column $(12.5 \mathrm{~mm} \times 4.6 \mathrm{~mm})$ at $35^{\circ} \mathrm{C}$. All injections were performed 
automatically using a $20 \mu \mathrm{L}$ loop on an Agilent C1329A ALS auto sampler apparatus. Detection of the analytes was carried out using Agilent multi wavelength UV - Vis detector (G1365C MWDSL, Agilent, USA).

The analyses were separated by running a mobile phase consisting of acidified water (A) acetonitrile (B) and methanol (C) at a flow rate of $1 \mathrm{ml} / \mathrm{min}$ through the column, $\mathrm{UV}-\mathrm{Vis}$ absorbance in the range of $250-370 \mathrm{~nm}$ at $28^{\circ} \mathrm{C}$. The composition of the mobile phase used in this study was held constant at A90:B10 (v/v) to give a total run time of 60 min for phenolic acid determination, while the mobile phase composition was maintained at A60:B15:C25 (v/v) with 40 min of running time to identify the flavonoids. On the other hand, the presence of gingerol and its derivatives was assessed through a constant mobile phase flow rate at $\mathrm{A} 50: \mathrm{B} 50(\mathrm{v} / \mathrm{v})$ for $40 \mathrm{~min}$.

The mobile phase used in this study was filtered under a vacuum through a $0.45 \mu$ m nylon membrane filter prior to use. All experiments conducted in the isocratic mode and all calculations to quantify the existence of active constituents were performed with external standards (6 - gingerol, 8 - gingerol, 10 - gingerol, 6 - shogaol, gallic acid, chlorogenic acid, ascorbic acid, vanillic acid, ferulic acid and p-coumaric) by measurement of peak areas. A calibration curve was drawn using six concentrations of the analytes, separately. All analyses were conducted in triplicate.

\subsection{Statistical Analysis}

All experiments were carried out in triplicate and presented as mean and standard deviation. One-way analysis of variance (ANOVA) was used to analyse the data using SPSS ${ }^{\text {TM }}$ software for Windows, Version 21.0 (SPSS Inc., Chicago, IL). The means were compared with Duncan's multiple comparison test (DMCT) and the differences among samples were analyzed using the least significant difference (LSD) test with a significance level of $\mathrm{p}<0.05$. Pearson correlation analysis was conducted to determine the correlation between the various parameters.

\section{RESULTS AND DISCUSSION}

\subsection{Identification of Phenolic Acids}

Gallic acids, chlorogenic acid, vanillic acid, p-coumaric acid, ferulic acid and trans-cinnamic acid, 6 - gingerol, 8 gingerol, 6 - shogaol and 10 - gingerol were the phenolic acids components identified in the current work. The retention times (Rt) for gallic acid was $4.9 \mathrm{~min}, 12.36 \mathrm{~min}$ for chlorogenic acid, $18.35 \mathrm{~min}$ for vanillic acid, $38.44 \mathrm{~min}$ for p-coumaric acid, 51.58 min for ferulic acid, $55.14 \mathrm{~min}$ for trans-cinnamic acid (Figure 1). While the retention time of 6 - gingerol was approximately 8.30 min, 8 - gingerol (15.84 $\mathrm{min}$ ), 6 - shogaol (19.53 $\mathrm{min}$ ) and $35.54 \mathrm{~min}$ for 10 - gingerol are shown in Figure 2. The HPLC chromatogram of phenolic acids (gallic acids, chlorogenic acid, vanillic acid, p-coumaric acid, ferulic acid and trans-cinnamic acid) and gingerols and its derivatives for coarse, fine and nanoparticle Z. officinale are presented in the Figure 3 and Figure 4 respectively.

The retention times (Rt) for gallic acid was $4.9 \mathrm{~min}, 12.36 \mathrm{~min}$ for chlorogenic acid, $18.35 \mathrm{~min}$ for vanillic acid, 38.44 min for p-coumaric acid, $51.58 \mathrm{~min}$ for ferulic acid, $55.14 \mathrm{~min}$ for trans-cinnamic acid (Figure 1).

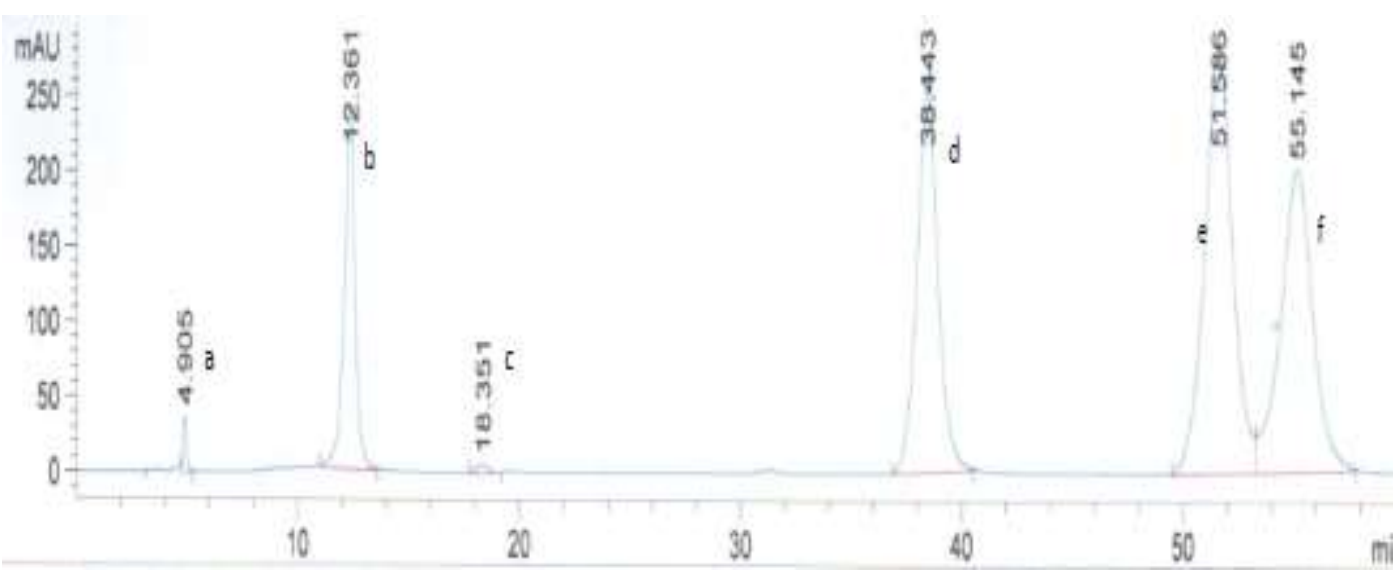

Figure 1: retention time (rt) of a: gallic acid; b: chlorogenic acid; c:vanillic acid; d: p-coumaric acid; e:ferulic acid; f: trans-cinnamic acid 
While the retention time of 6 - gingerol was approximately $8.30 \mathrm{~min}, 8$ - gingerol (15.84 $\mathrm{min}), 6$ - shogaol (19.53 min) and 35.54 min for 10 - gingerol are shown in Figure 2.

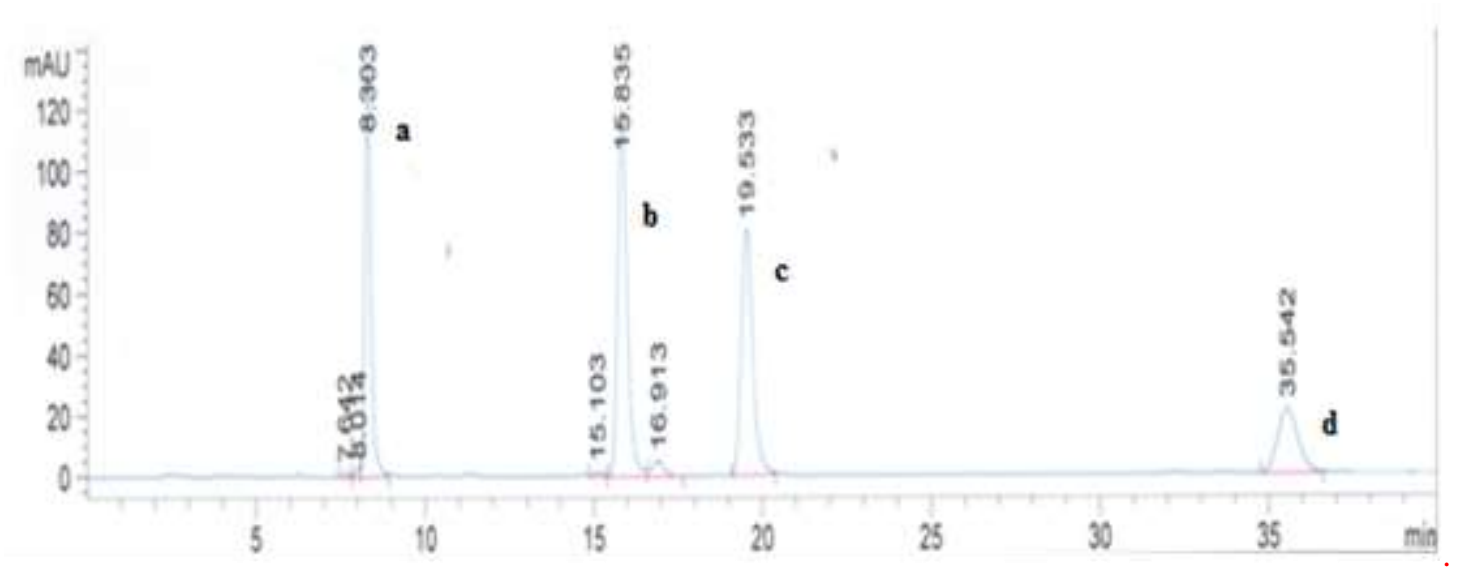

Figure 2: Retention time (rt) of a: 6 - gingerol; b: 8 - gingerol; c: 6 - shogaol; d: 10 - gingerol

In the current work, changes in the phenolic acids include gingerols in Z. officinale rhizome due to the nanotechnology process were identified and ascertained by high pressure liquid chromatography (HPLC) with 17 standard references and are presented in Table 1.

Table 1. Phenolic acids profile of coarse particle, fine particle and nanoparticle Z. officinale rhizome

\begin{tabular}{|c|c|c|c|c|}
\hline \multirow{2}{*}{ Phenolic Acids } & \multirow{2}{*}{$\begin{array}{c}\text { Retention Time } \\
\text { (Rt) }\end{array}$} & \multicolumn{2}{|c|}{ Content (mg/g of dw) } & \multirow[b]{2}{*}{ Nanoparticle } \\
\hline & & Coarse Particle & Fine Particle & \\
\hline Gallic acid & 4.90 & $3.73^{b}$ & $5.55^{\mathrm{a}}$ & $1.46^{c}$ \\
\hline Chlorogenic acid & 12.36 & $0.86^{c}$ & $1.44^{\mathrm{a}}$ & $0.95^{\mathrm{b}}$ \\
\hline Vanillic acid & 18.35 & $0.57^{\mathrm{b}}$ & $0.46^{\mathrm{c}}$ & $0.78^{\mathrm{a}}$ \\
\hline p- Coumaric acid & 38.44 & n.d & $1.05^{\mathrm{a}}$ & n.d \\
\hline Ferulic acid & 51.58 & n.d & n.d & n.d \\
\hline Trans-Cinnamic Acid & 55.14 & n.d & n.d & n.d \\
\hline 6 - gingerol & 8.30 & $2.08^{c}$ & $2.67^{b}$ & $22.31^{\mathrm{a}}$ \\
\hline 8 - gingerol & 15.84 & $4.29^{c}$ & $12.96^{\mathrm{a}}$ & $12.99^{\mathrm{a}}$ \\
\hline 10 - gingerol & 35.54 & $1.52^{\mathrm{b}}$ & n.d & $2.03^{\mathrm{a}}$ \\
\hline 6-shogaol & 19.53 & n.d & $21.50^{\mathrm{c}}$ & n.d \\
\hline Total Phenolic Acid & & $13.05^{\mathrm{c}}$ & $45.63^{\mathrm{a}}$ & $40.52^{\mathrm{b}}$ \\
\hline
\end{tabular}

In all samples tested, 8-gingerol acid showed the highest concentration, followed by 6-gingerol, gallic acid, chlorogenic acid, vanillic acid and p-coumaric acid. On the other hand, ferulic acid and trans-cinnamic acid were not detected in any of the samples tested. The results revealed that nanotechnology process found to increase the gingerols level as depicted by significantly high gingerols concentration in the nanoparticle $Z$. officinale rhizome as compared to the coarse and fine particle samples (Figure 1.2). Increased in the 6 - gingerol (28.37\%), 8 - gingerols (36.03) as well as 6 -shogaol (100\%) with totally undetectable 10 gingerol in the fine particle when compared to the coarse particle $(\mathrm{p}<0.05)$. The concentration was significantly increased when the particle size was further reduced into nanoparticle.

The nanotechnology process caused an increment of $88.03 \%$ in 6 - gingerol, $0.23 \%$ in 8 - gingerol and $100 \%$ in 10 gingerol more than fine particle $(\mathrm{p}<0.05)$. However, 6 - shogaol was not detected in the nanoparticle Z. officinale rhizome sample. In total, nanoparticle Z. officinale sample contained the highest concentration of gingerol and gingerol derivatives while the coarse particle contained the lowest. In conclusion, the gingerol and gingerol derivatives contents were in the ascending order of nanoparticle > fine particle > coarse particle. The data obtained revealed that the gingerols content was found to be increased with decrease in the particle size. 
In terms of weight basis, 8 - gingerol was the dominant gingerol found in coarse and fine particles while 6 - gingerol was found abundantly in the nanoparticle $Z$. officinale rhizome. However, in the current work, 6 - shogaol was only detected in the fine particle sample. The results obtained slightly differed from other studies where they reported that the main active compounds commonly found in Z. officinale rhizome were 6 - gingerol and 6 - shogaol (Rani et al., 2012; Zhan et al., 2011). Figure 3 shows the amount of gingerol and gingerol derivatives in different particle size of $Z$. officinale rhizome.

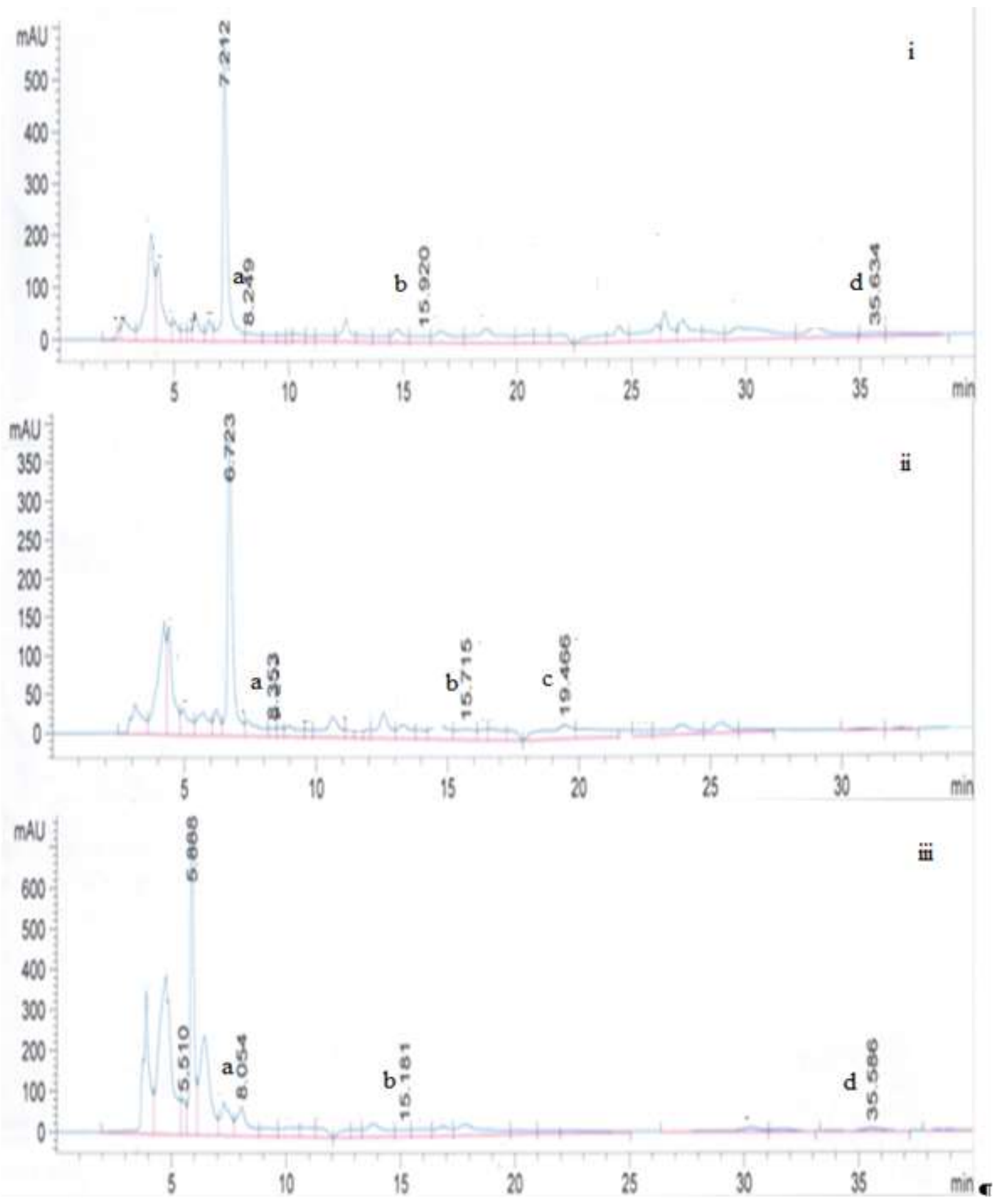

Figure 3: HPLC chromatograms of gingerol and gingerol derivatives in i; coarse; ii; fine; and iii; nanoparticle $Z$. officinale rhizome

Note: $\mathrm{a}=6$ - Gingerol; $\mathrm{b}=8-$ Gingerol; $\mathrm{c}=6-$ Shogaol; $\mathrm{d}=10-$ Gingerol

Among all, nanoparticle Z. officinale rhizome contained the highest amount of 6 - gingerol $(88.03 \%-90.68 \%)$ as compared to the coarse and fine particles respectively $(\mathrm{p}<0.05)$. The results obtained show the nanotechnology process retained 6 gingerol content, while most probably it was shifted to 6 - shogaol in the fine particle sample. The changes were due to heat generated during processing and long term storage since both factors lead to shifting of 6 - gingerol to 6 - shogaol [15, 16]. 6- 
gingerol is the commonly active constituent found in Z. officinale, also known as 5-hydroxy-1-(4-hydroxy-3- methoxyphenyl) decan-3-one with chemical formula of $\mathrm{C}_{17} \mathrm{H}_{26} \mathrm{O}_{4}$. While 6 Shogaol, the dehydrated form of gingerol, known as (E)-1-(4-Hydroxy3- methoxyphenyl) dec-4-en-3-one has the molecular formula of $\mathrm{C}_{17} \mathrm{H}_{24} \mathrm{O}_{3}$. The formation of shogaol takes place by dehydration of one molecule of water from the parent compound of 6- gingerol [17].

The high level of 6 - gingerol in the nanoparticle sample showed the high quality of Z. officinale produced, since 6 gingerol has been used as a marker substance for high quality fresh Z. officinale rhizome [18, 19]. However, the results revealed that nanotechnology caused loss in some phenolic acid. The HPLC chromatogram of phenolic acids (gallic acids, chlorogenic acid, vanillic acid, ferulic acid and trans-cinnamic acid) for coarse, fine and nanoparticle Z. officinale are presented in the Figure 4 below.

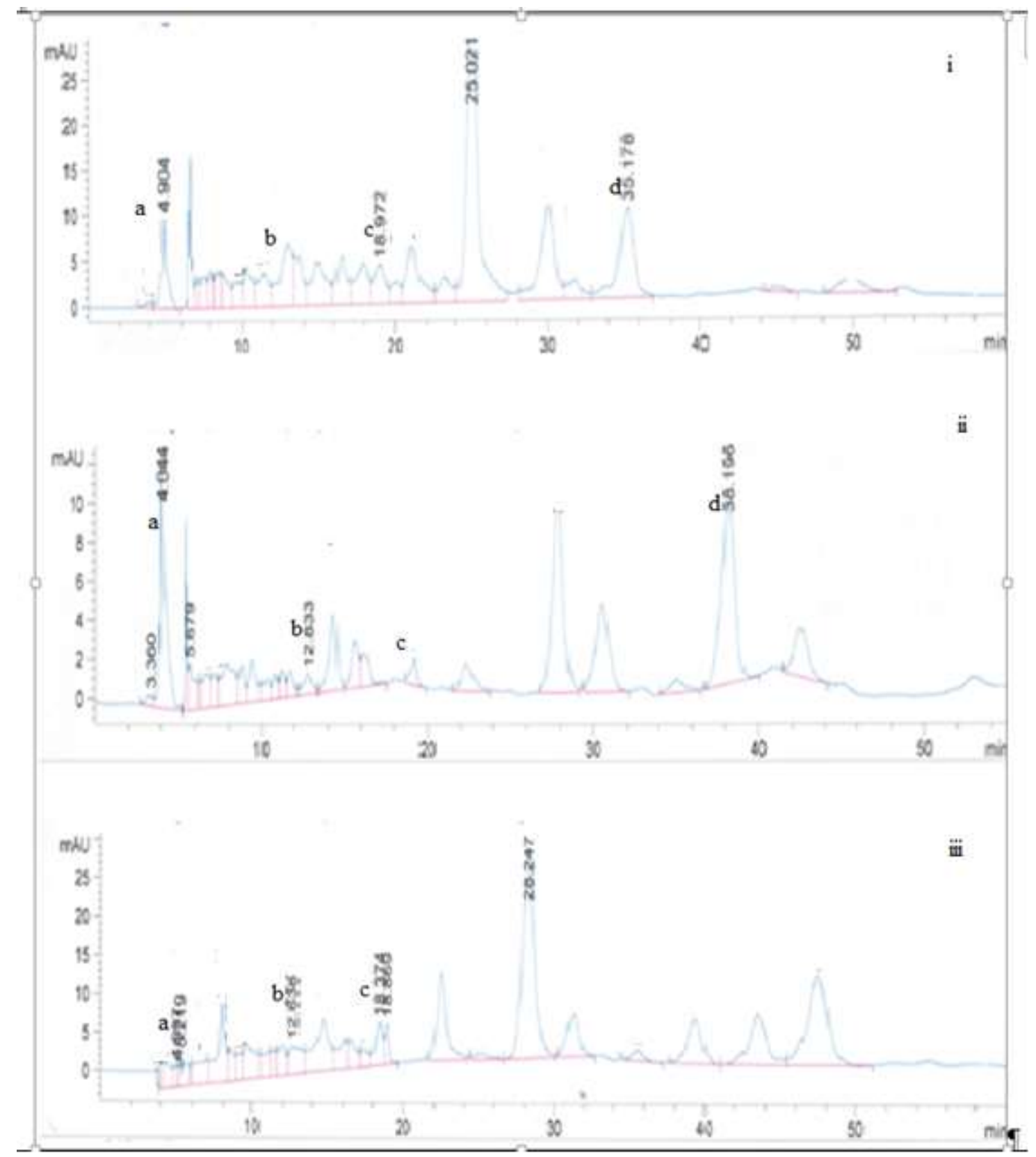

Figure 4: HPLC chromatogram of phenolic acids in i; coarse; ii; fine; and iii; nanoparticle $Z$. officinale rhizome Note: a: Gallic Acid; b:Chlorogenic Acid; c:Vanillic Acid; d: p-Coumaric Acid; e:Ferulic Acid; f: Trans-Cinnamic Acid

Initially there were increased in the gallic acid (48.79\%), chlorogenic acid (67.44\%), and p-coumaric acid (almost 100\%) while there was a significant decrease in vanillic acid (19.29\%) in the fine particle as compared to coarse particle. It is expected that increased in the active constituent may occur with decrease in the particle size; however, in the current work the results revealed that concentration of phenolic acids was not particle size dependent. 
It was found that the nanotechnology process reduced about $74 \%$ the concentration of gallic acid, chlorogenic acid (34.13\%) and p-coumaric acid (almost 100\%) as observed in nanoparticle Z. officinale rhizome when compared to fine particle which indicated that the nanotechnology process leads to significant alteration in the $Z$. officinale phenolic acids contents and in most of the phenolic acids, the measured parameters decreased.

Phenolic acid loss due to the nanotechnology process was also reported in the previous study. Some loss of folates, phytic acid and sinapic acid observed in ultrafine wheat bran [8], while significant loss of coumaric acid (76.71\%) and ferulic acid (47.88\%) in fibre flax [7]. The possible reason for this situation was the phenolic acid's degree of stability and it may be that, to a certain extent, some of the phenolic acids were thermally unstable. In the study conducted by [20] it showed that syringic, ferulic and sinapic acids were stable up to $150^{\circ} \mathrm{C}$ with only $90^{\circ} \mathrm{C}$ for vanillic acid. While in another study, revealed that ferulic acid was readily degraded by $73.4 \%$ when stored for 10 weeks at $40^{\circ} \mathrm{C}$ [21]. Moreover, the increase in the contact area of the particle due to the nanotechnology process may simultaneously increase the contact area of phenolic acids to $\mathrm{O}_{2}$ which promotes phenolic acid oxidation that may reduce the concentration of phenolic acids, especially those easily oxidised. Even so, [20] et al. stated that easily oxidised phenolic acid (gallic acid) was more tolerance to the thermal effect as compared to less oxidisable ones (ferulic acid) when totally loss of ferulic acid with increased temperature. In contrast temperature increased only caused some loss of gallic acid concentration. Thus the author concluded that both $\mathrm{O}_{2}$ and temperature play an important role in ensuring the phenolic acids' stability. The instability of ferulic acid with temperature and the more tolerance observed in gallic acid [20] may be the reason for totally undetectable ferulic acid in any size of $Z$. officinale rhizome particle, while a decrease in the gallic acid was obtained in the current work with size reduction.

However it is being reported that nanotechnology process leading to $1.22 \mathrm{mg} / \mathrm{g}$ higher salvianolic acid B in nano $S$. miltiorrhiza than those in coarse particles which indicated that the nanotechnology process increased some of the phenolic acid [6]. The similar phenolic acids increment as a result of the nanotechnology process was also encountered in the nanoparticle $Z$. officinale prepared in the current work. It was found that $69.56 \%$ of vanillic acid increment was encountered in the nanoparticle $Z$. officinale as compared to the coarse and fine particles. The stability of vanillic acid towards heat and oxidation may be the possible reason for this since among all, vanillic acid is classified as the less oxidised and more stable phenolic acid [20]. Increased in some of the phenolic acids as a result of the nanotechnology process have also has been reported by Tao et al. (2014) when $12.56 \%$ of chlorogenic acid and $38.06 \%$ of ferulic acid increment were observed in dietary fibre from pomace which contrasts with the results obtained in the current work. Most probably, the shorter milling times of 8 mins to prepare the ultrafine dietary fibre from pomace, as compared to 4 hours to prepare the nanoparticle Z. officinale used in the current work had contributed to the variation in the phenolic acids detected. longer milling times could increase the mill cavity temperature which further promotes more loss of unstable active compounds [22].

\section{CONCLUSION}

HPLC analysis showed that gallic acids, rutin and 8-gingerol are the phenolic acids and gingerol compounds found abundantly in all particle size of $Z$. officinale rhizome samples studied. Nanotechnology found to increase the concentration of gingerol and its derivatives but caused some depleted in less stable phenolic acids as indicate in significantly high phenolic acids concentration in fine particles, while the nanoparticle Z. officinale rhizome exhibited the lowest. Hence it can be suggested that, nanotechnology did affect the phenolic acids profile of $Z$. officinale rhizome.

\section{ACKNOWLEDGMENT}

The authors are grateful to the Ministry of Education, Malaysia for the scholarship in carrying out this research.

\section{REFERENCES}

1. H. Bouwmeester, S. Dekkers, M. Y. Noordam, W. I. Hagens, A. S. Bulder, C. de Heer, S. E. C. G. ten Voorde, S. W. P. Wijnhoven, H. J. P. Marvin, and A. J. A. M. Sips, "Review of health safety aspects of nanotechnologies in food production," Regulatory Toxicology and Pharmacology, vol. 53, pp. 52-62, 2009.

2. D. V. Ratnam, D. D. Ankola, V. Bhardry Weightaj, D. K. Sahana, and M. N. Kumar, "Role of antioxidants in prophylaxis and therapy: a pharmaceutical perspective," Journal of Controlled Release, vol. 113, pp. 189-207, 2006.

3. M. S. Giao, C. I. Pereira, S. C. Fonseca, M. E. Pintado, and F. X. Malcata, "Effect of particle size upon the extent of extraction of antioxidant power from the plants Agrimonia eupatoria, Salvia sp. and Saturej a Montana. ," Food Chemistry, vol. 117, pp. 412-416, 2009.

4. G. Zhao, C. Wang, Z. Liao, X. Liang, Y. Cao, and X. Chen, "Comparative study of physicochemical properties of dragon's blood powders," Advanced Materials Research, vol. 311-313, pp. 560-565, 2011. 
5. P. Y. Ma, Z. Y. Fu, Y. L. Su, J. Y. Zhang, W. M. Wang, and H. Wang, "Modification of physicochemical and medicinal characterization of Liuwei Dihuang particles by ultrafine grinding," Powder Technology, vol. 191, pp. 194-199., 2009.

6. J. R. Liu, G. F. Chen, H. N. Shih, and P. C. Kuo, "Enhanced antioxidant bioactivity of Salvia miltiorrhiza (Danshen) products prepared using nanotechnology," Phytomedicine, vol. 15, pp. 23-30., 2008.

7. L. Dyminska, M. Szatkowski, M. Wrobel Kwiatkowska, M. Zuk, A. Kurzawa, and W. Syska, "Improved properties of micronized genetically modified flax fibers," Journal of Biotechnology, vol. 164, pp. 292-299, 2012.

8. M. Y. Hemery, N. M. Anson, R. Havenaar, R. M. M. G. Haenen, W. J. M. Noort, and X. Rouau, "Dry-fractionation of wheat bran increases the bioaccessibility of phenolic acids in bread made from processed bran fractions," Food Research International, vol. 43, pp. 1429-1438, 2010.

9. I. Sasidharan and A. N. Menon, "Comparative chemical composition and antimicrobial activity fresh \& dry ginger oils (Zingiber Officinale Roscoe)," International Journal of Current Pharmaceutical Research, vol. 2, 2010.

10. H. Mohamad, Y. Andriani, M. A. W. Effendy, and T. M. T. Sifzizul, "Antibacterial, radical- scavenging activities and cytotoxicity properties of Phaleria macrocarpa (scheff.) boerl. leaves in hepg2 cell lines," International Journal of Pharmaceutical Sciences and Research, vol. 2 pp. 1700-1706, 2011.

11. S. Ok and W. S. Jeong, "Optimization of Extraction Conditions for the 6-Shogaol-rich Extract from Ging er (Zingiber officinale Roscoe): Research Note," Previiew Nutrition and Food Science, vol. 17, pp. 166 - 171, 2012.

12. L. A. Pacheco Palencia, C. E. Duncan, and S. T. Talcott, "Phytochemical composition and thermal stability of two commercial açai species, Euterpe oleracea and Euterpe precatoria," Food Chemistry, vol. 115, p. 1199-1205, 2009.

13. A. Ghasemzadeh, H. Z. E. Jaafar, and A. Rahmat, "Synthesis of phenolics and flavonoids in ginger (Zingiber officinale Rosc) and their effects on photosynthesis rate," International Journal of Molecular Science, vol. 11, pp. 4539-4555, 2010.

14. M. Rani, M. S. Krishna, K. P. Padmakumari, K. G. Raghu, and A. Sundaresan, "Zingiber officinale extract exhibits antidiabetic potential via modulating glucose uptake, protein glycation and inhibiting adipocyte differentiation: an in vitro study," Journal of Science Food and Agriculture, vol. 92, pp. 1948-1955, 2012.

15. C. Lee, G. H. Park, C. Y. Kim, and J. H. Jang, "[6]-gingerol attenuates b-amyloid-induced oxidative cell death via fortifying cellular antioxidant defense system," Food and Chemical Toxicology, vol. 49, pp. 1261-1269, 2011.

16. K. Zhan, K. Xu, and H. Yin, "Preparative separation and purification of gingerols from ginger (Zingiber o Officinale Roscoe) by high-speed counter-current chromatography. ," Food Chemistry, vol. 126, pp. 1959-1963, 2011.

17. S. Gopi, K. Varma, and S. Jude, "Study on the temperature-dependent conversion of active components of ginger," International Journal of Pharma Sciences, vol. 6, pp. 1344-1347, 2016.

18. H. A. Schwertner and D. C. Rios, "High-performance liquid chromatographic analysis of 6-gingerol, 8-gingerol, 10gingerol, and 6-shogaol in ginger-containing dietary supplements, spices, teas, and beverages. ," Journal of Chromatography B, vol. 856, pp. 41-47, 2007.

19. H. Y. Young, Y. L. Luo, H. Y. Cheng, W. C. Hsieh, J. C. Liao, and W. H. Peng, "Analgesic and anti-inflammatory activities of [6]-gingerol," Journal of Ethnopharmacology, vol. 96, pp. 207-310, 2005.

20. Z. Reblova, "Effect of temperature on the antioxidant activity of phenolic acids. Czech " Journal of Food Sciences vol. 30, pp. 171-177., 2012.

21. L. A. Pacheco Palencia, Duncan, C. E., \& Talcott, S. T. , C. E. Duncan, and S. T. Talcott, "Phytochemical composition and thermal stability of two commercial acai species, Euterpe oleracea and Euterpe precatoria," Food Chemistry, vol. 115, pp. 1199-1205, 2009. 